\title{
ENVIRONMENTAL ASSESSMENT OF HEAVY METAL CONTAMINATION IN \\ YELLOWSTONE NATIONAL PARK
}

\author{
Allen Medine \\ Stephen Klein \\ Civil and Environmental Engineering \\ University of Colorado \\ Boulder
}

\section{Objectives}

Heavy metals in our National Parks and Forest, their transport processes, environmental distributions and biological effects have been the focus of increasing concern. Direct toxicity to higher organisms and man are the center of this concern, with transport phenomena, ultimate fate and aqueous chemistry as further focus points. It is well known that heavy metal concentrations in soils, plants, and water along heavily traveled roads tend to show increased levels compared to control sites. The current research is to assess the contamination of roadside waters of Yellowstone National Park due primarily to the intensive summer automobile traffic and increasing winter visitation and oversnow vehicles.

The objectives of the research are to define the level of metal contamination within Yellowstone National Park through a combined analysis of environmental transport, bioaccumulation and environmental chemistry. Specific objectives which will provide a detailed analysis and assessment of contamination and its significance to the health of the aquatic environments and park visitor include:

1. Determine metal concentrations $(\mathrm{Pb}, \mathrm{Cu}, \mathrm{Cd}, \mathrm{Ni}, \mathrm{Zn})$ in surface waters. The analysis will include various compartments - water, sediments, plants, invertebrates, zooplankton, and fish;

2. Establish migration distances from points of maximum exposure to metal sources;

3. Assess bioaccumulation within food chains and potential health implications from fish consumption in the study areas;

4. Correlate the above findings with the vehicle use levels in the representative areas;

5. Examine historical and present patterns of metal accumulation within the sediments of lake systems; and

6. Evaluate the results of the research with MEXAMS (the Metals Exposure Analysis Modeling System) to assist management plans.

\section{Methods}

The methodology for the research is based on previous research in which heavy metals have been examined in various compartments of the White River 
ecosystem (Medine, Lamara, and Carter, 1983), lead contamination was investigated in the Indian Peaks Wilderness Area of the Colorado front range (Medine and Flack, 1984), and other investigations on Lake Powell, UT/AZ, the Naugatuck River, Conn., and the Clear Creek, CO.

The research is concentrating on waters in near proximity to roads within the Park which receive various levels of use and utilize control areas which are removed from recreational impacts. Sampling for water quality has been performed on a biweekly schedule while biota sampling was monthly and sediment sampling once/year. The frequency of water quality sampling is necessary to establish temporal variability of dissolved metal levels, an important factor when assessing metal stress within an aquatic ecosystem. Biological and sediment sampling are less frequent due to smaller temporal variations (within one season) and to reduce analytical costs while still maintaining a comprehensive study. Important components of both lentic and lotic waters of the Park have been sampled to document level and extent of contamination. Transects within major water bodies will establish migration distances from points of maximum traffic, while sediment coring will determine the historical pattern of metal accumulation and current trends.

Atmospheric migration distances of vehicular metal emissions was monitored with deposition samplers at several locations. Four control sites, Upper Lamar Valley, Grebe Lake, Clear Creek and Riddle Lake each had one sampler changed on a monthly basis. Transects normal to roadways were established at two locations, Hayden Valley and Sand Point. These consisted of four to seven samplers on each side of the road extending out as far as 400 meters. Interference by wildlife, particularly buffalo, with these samplers was experienced. As a measure of both horizontal and vertical migration, sectioned soil cores on the same transects were collected. Analysis is not complete at this time.

Complete sampling of sites for physical and biological components was conducted in August and September. The biological samples were divided into several compartments: mayfly nymphs, stonefly nymphs, dragonfly nymphs, caddisfly larvae, snails, scuds, fish and plants. Stoneflys were subdivided into herbivores, predators, and, depending on biomass, size classes. Whenever observed, emerging aquatic insects were collected along with their exuviae. Fish were not collected from all sites as they have generally been shown to be unreliable indicators of water quality due to their mobility. Fish tissues were divided into flesh, liver and stomach contents. Depending on availability, size, sex and specie classes were collected. Sediments collected were divided into coarse and fine fractions, and where substrate was favorable, periphyton was scraped.

Intact sediment cores were collected on transects in Yellowstone, Lewis and Sylvan Lakes. These cores were sectioned every $2 \mathrm{~cm}$ (about 10 years of deposition) for the first $20 \mathrm{~cm}$ (100 years) and the remaining core sectioned in 5 $\mathrm{cm}$ intervals. Additional core sections were obtained from Dr. Jerry Kaster of Great Lakes Research Center (July 1984). The contamination in the cores will be compared with data on park visitation since the 1940's when leaded gas was introduced. 
The initial visit to the Park during the last week of May was made to survey the proposed sample sites and collect water samples from most major streams. Sampling continued until the end of September with a weeklong break in June and August for sample processing and modification of field equipment. October and November were spent analyzing water samples and collecting data on visitor activities in the Park.

Planned sampling programs (as proposed) were closely followed with slight modification based upon site surveys, Fish and Wildlife Service recommendations, closures for bear management and consideration for avoiding public view during sampling. Several locations of special interest were added: Bridge Bay - intensive boat usage; Sylvan, Scaup and Floating Island Lakes close proximity to roadways; Trout Creek - downstream from dump; Pelican and Clear Creeks - major spawning streams for cutthroat trout. With in excess of 600 water, 300 biology, 250 sediment and 50 bulk atmospheric deposition samples collected, a substantial data base will be generated to permit a definition of aquatic environmental quality throughout the Park.

\section{$\underline{\text { Results }}$}

Analysis of samples began with a high priority attached to filtered water samples. The data for dissolved lead, zinc and copper from samples collected in May is shown in Table 1. Dissolved metal concentrations in water samples from throughout the Park have generally been low with lead $<1 \mathrm{ppb}(u \mathrm{~g} / 1)$, zinc $<3$ $\mathrm{ppb}$ and copper < $4 \mathrm{ppb}$. Before any conclusions can be drawn additional analysis must first be completed on water and other compartments. For example, dissolved lead at a control site on the upper Gibbon River is about 100 ppt (ng/1), 400 ppt in Scaup Lake (a roadside lake) and $700 \mathrm{ppt}$ in Bridge Bay on Yellowstone Lake. However, lead in detritus is $17 \mu \mathrm{g} / \mathrm{g}, 320 \mu \mathrm{g} / \mathrm{g}$ and 11,200 $\mathrm{mg} / \mathrm{g}$, respectively. The latter two levels are indicative of contamination compared to other contaminated and uncontaminated systems. These levels are significant in that detritus is a food source for benthic dwelling organisms and a route by which metal may be accumulated. The data, while limited at present, is consistent with our understanding of metal transport and fate and suggests that the complete data set will allow a regional and local assessment of metal contamination. It is highly possible that the low ionic strength, the chemistry of thermal waters and high $\mathrm{pH}$ 's are contributing to metal partitioning to benthic regions through adsorption, precipitation and/or coprecipitation. The possible impacts to aquatic organisms cannot be addressed until the analysis is complete.

Temporal variations on the Firehole River indicate that the water quality for zinc is not changing dramatically in a logitudinal patterns. It has not been determined whether the decrease in zinc downstream is due to dilution or to sediment removal. Samples from Soda Butte Creek for copper indicate a similar response. Three locations on the Lamar River, however, show considerable temporal variability in copper. The high levels observed $(5-20 \mu \mathrm{g} / 1$ ) frequently indicate a need for additional sampling next summer.

Concentration of lead, zinc, and copper in sediments, detritus, scuds, fish and snails for selected locations are shown in Table 2. The data shows general 
Table 1. Dissolved lead and zinc concentrations in surface waters during May, 1984.

Dissolved Metal, $\mu \mathrm{g} / \mathrm{l}$

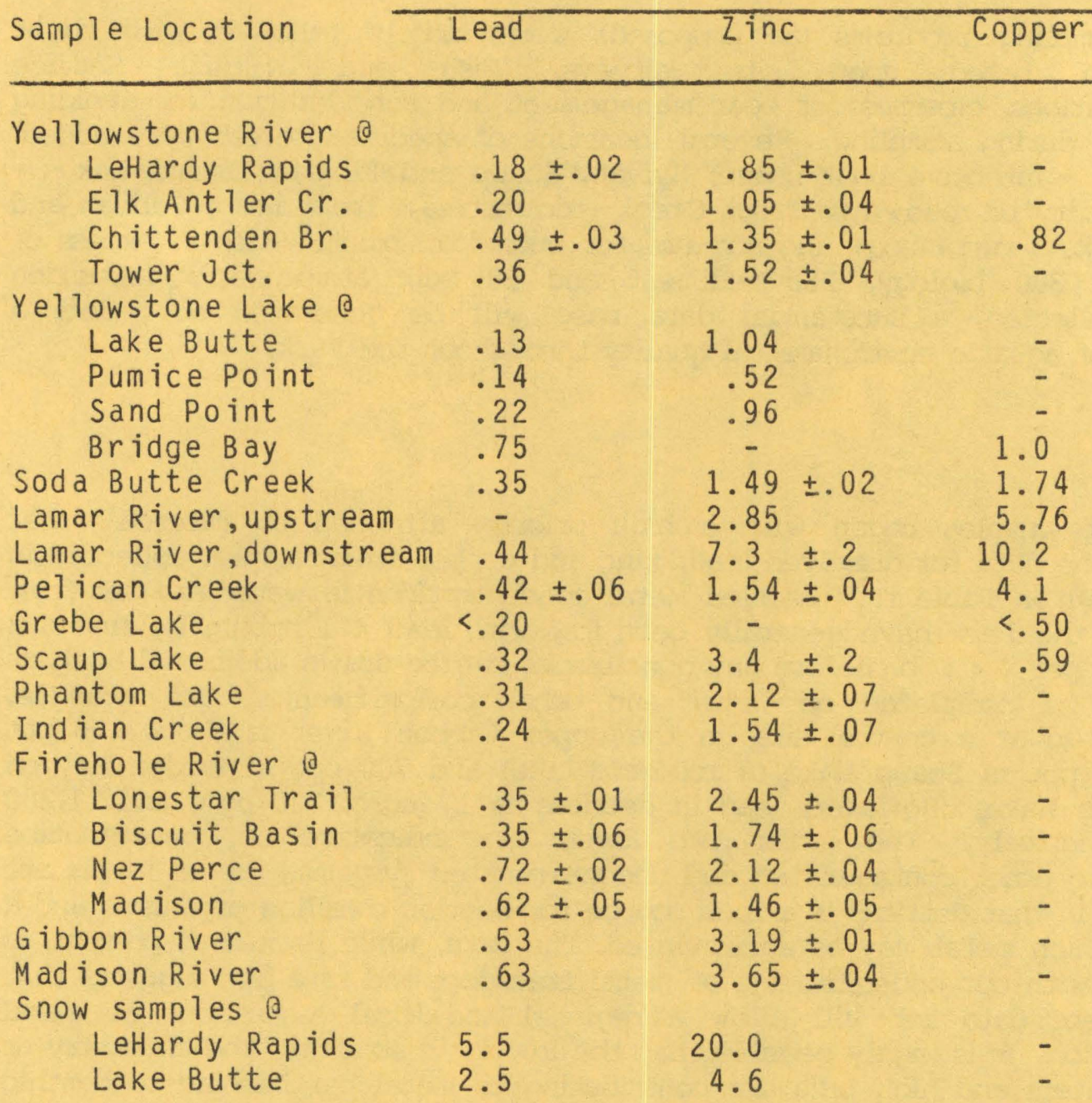

The concentrations are means + - standard deviation in ug/T $(p p b)$ based on actual instrument precision and accuracy. The missing samples have not been analyzed at present. 
Table 2. Metal concentrations in sediments, detritus, scuds, fish and snails in selected surface waters.

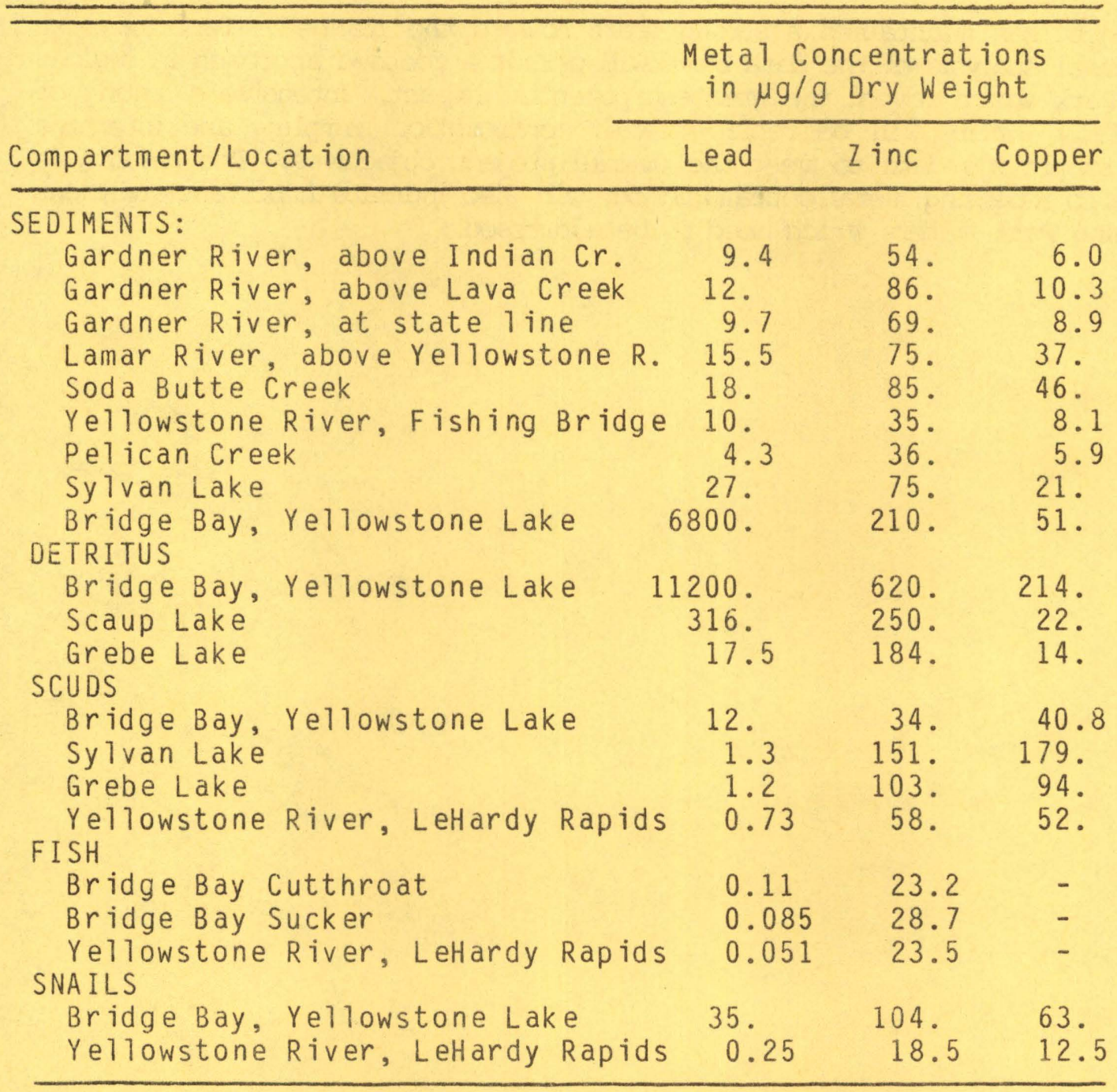


levels in representative waters as well as significant contamination in areas with a high metal mass loading to environmental volume ratio, i.e. Bridge Bay in Yellowstone Lake, Scaup Lake and Sylvan Lake. This is very tentative data and represents less than $4 \%$ of the samples collected.

The project has maintained a strong start toward the planned effort for next year. Final analysis of the data base will permit a focused approach in regions of the Park which reveal the greatest potential impact. Intensive sampling of the surface waters will be replaced with confirmation sampling and intensive studies to provide data to meet the overall project objectives. The results, in addition to assessing metal contamination, will also indicate important questions concerning Park waters which need to be addressed. 